\title{
HDPE/ZnO ve HDPE/Hidroksiapatit Nanokompozitlerin Termal ve Morfolojik Özelliklerinin İncelenmesi
}

\author{
Betül ÇIÇEK ÖZKAN ${ }^{1 *}$, Melek GÜNER ${ }^{2}$, Tarık Selçuk ŞEKER ${ }^{3}$ \\ Metalurji ve Malzeme Mühendisliği Bölümü, Teknoloji Fakültesi, Fırat Üniversitesi, Elazığ, Türkiye \\ ${ }^{* 1}$ bcozkan@ firat.edu.tr, ${ }^{2}$ mggunermelek@gmail.com, ${ }^{3}$ tarikselcukseker@gmail.com
}

(Geliş/Received: 28/10/ 2019;

Kabul/Accepted: 13/02/2020)

\begin{abstract}
Öz: Yüksek yoğunluklu polietilen (HDPE) matrisine farklı oranlarda çinko oksit (ZnO) ve hidroksiapatit (HAp) nano parçacıklar takviye edilerek baskı tekniği ile farklı konsantrasyonlarda nanokompozit malzemeler üretilmiştir. Kullanılan nano takviye malzemelerinin ve kompozit üretim yönteminin HDPE matrisli kompozitler üzerindeki termal, morfolojik ve kristalinite özellikleri araştırılmıştır. Hazırlanan kompozitlerin X-ışını kırınım deseni (XRD) yöntemi kullanılarak kristalinite özellikleri incelenmiş ve HDPE'nin karakteristik $2 \theta$ pikleri elde edilmiştir. HDPE/ZnO nanokompoziti için ZnO fazına ait olan $2 \theta$ pikleri tespit edilmiş ve ortalama kristal boyutunun 14 ile $26 \mathrm{~nm}$ arasında değiștiği belirlenmiştir. HDPE/HAp nano kompozitinde HAp fazına ait olan $2 \theta$ pikleri ve ortalama 10 ile $25 \mathrm{~nm}$ arasında değişen kristal boyutları tespit edilmiştir. XRD sonuçları her iki kompozit içerisinde nano takviye malzemelerinin iyi bir biçimde dağıldığını göstermektedir. Ayrıca artan takviye miktarı ile kompozitin kristalinitesinin arttığı belirlenmiştir. Termal analiz sonucunda her iki kompozit grubu için tespit edilen takviye oranının gerçek değerlerle örtüştüğü ve artan takviye miktarıyla 1sı akısının arttığı belirlenmiştir. Morfolojik incelemeler sonucunda nanokompozit malzemelerin yüzey yapısının saf HDPE'den farklı olduğu, tabakalanmaların meydana geldiği ve artan takviye miktarıyla bu değişimin daha net bir biçimde görüldüğü gözlenmiştir.
\end{abstract}

Anahtar kelimeler: Çinko oksit ( $\mathrm{ZnO})$, hidroksiapatit (HAp), nanokompozit, termal stabilite, yüksek yoğunluklu polietilen (HDPE).

\section{Thermal and Morphological Properties of HDPE/ZnO and HDPE/HAp Nanocomposites}

Abstract: Nanocomposite materials in different concentrations were produced through printing technique by adding zinc oxide $(\mathrm{ZnO})$ and hydroxyapatite (HAp) nanoparticles in different ratios into high density polyethylene (HDPE) matrix. Thermal, morphological and crystallinity properties of nano reinforcing materials and composite production method on HDPE matrix composites were investigated. Crystallinity properties of the composites were investigated by using the X-ray diffraction pattern (XRD) and the characteristic $2 \theta$ peaks of HDPE were obtained. $2 \theta$ peaks belonging to the $\mathrm{ZnO}$ phase for $\mathrm{HDPE} / \mathrm{ZnO}$ nanocomposite were obtained and the average crystal size ranged from 14 to $26 \mathrm{~nm}$ was determined. In HDPE/HAp nano composites, $2 \theta$ peaks of HAp phase and average crystal sizes ranging between 10 and $25 \mathrm{~nm}$ were determined. XRD results showed that the nano reinforcing materials were well dispersed in both composites. In addition, it was observed that the crystallinity of composite increased with the increase in the amount of reinforcing material. As a result of thermal analysis, it was determined that the reinforcement ratio determined for both composite groups coincided with the accurate values and the heat flux increased with increasing reinforcement amount. As a result of morphological investigations, it was observed that the surface structure of nanocomposite materials was different from pure HDPE, layering occurred and this change was observed more clearly with increasing amount of reinforcement.

Key words: High density polyethylene (HDPE), hydroxyapatite (HAp), nanocomposite, thermal stability, zinc oxide $(\mathrm{ZnO})$.

\section{Giriş}

Polietilen (PE) yaygın olarak kullanılan termoplastik malzemelerden biridir. PE türleri arasında ise yüksek kristalli yapısı sebebiyle yüksek yoğunluklu polietilen (HDPE) en sık kullanılandır [1]. Düşük maliyetli olması, daha az proses enerjisi gereksinimi ve kolay işlenebilmesi HDPE'i; torba, şişe, film ve boru vb. birçok uygulama için oldukça elverişli hale getirmektedir [2]. Diğer PE türleriyle kıyaslandığında HDPE yüksek çekme dayanımına, iyi mekanik ve termal özelliklere sahiptir [3-5].Son yıllarda nanokompozitlerin termal, optik, mekanik, elektronik ve katalitik özellikleri bakımından saf polimerlere göre çok daha üstün özelliklere sahip oldukları tespit edilmiştir.

\footnotetext{
* Sorumlu yazar: bcozkan @ firat.edu.tr. Yazarların ORCID Numarası: ${ }^{1}$ 0000-0002-8852-6650, ${ }^{2}$ 0000-0001-9990-9051, ${ }^{3}$ 0000-0001-71557963
} 
Yapılan araştırmalar nano katkı maddelerinin kompozit malzemelerin teknik özellikleri üzerinde olumlu etkiye sahip olduğunu göstermiştir [7]. Bu olumlu etkinin sebebi, nano yapıların yüzey alanlarının çok büyük olması ve bu durumun matris ile nano katkı maddesi arasındaki yapışmayı arttırmasıdır. Nano katkı maddelerinin diğer bir olumlu özelliği de polimer matris içerisinde kolayca ve homojen bir biçimde dağılabilmesidir [6]. ZnO, birçok bilimsel çalışmada ve günlük uygulamalarda yaygın olarak kullanılan ucuz ve çok yönlü yarı iletken bir malzemedir. ZnO katkılı polimerik nanokompozit malzemeler, ş̧ık yayan diyotlar [8], saydam iletkenler [9], UV koruyucu [10], gaz algılama sensörleri [11] ve benzeri uygulamalarda kullanılarak birçok bilimsel çalışmaya konu olmuş ve literatürde yer almıştır [12]. ZnO’nun düşük maliyetli olması, antibakteriyel özellik göstermesi, iyi fotokatalitik aktiviteye sahip olması, iyi gaz algılama özelliği göstermesi ve toksik olmaması birçok araştırma ve uygulamada çokça tercih edilmesinin başlıca sebeplerindendir. İnorganik nano dolgu maddeleri organik matrislere takviye edilerek daha iyi termal, mekanik, optik ve elektronik özelliklere sahip organik-inorganik nanokompozit malzemeler üretilmektedir [12].

ZnO katkılı HDPE nanokompozit malzemeler dikkat çeken özellikleri sebebiyle birçok araştırmanın başlıca konusu olmuşlardır. Mansour ve ark. [13], ZnO nanopartikülleri kullanarak HDPE/ZnO nanokompozitleri üretmiş ve bunların dielektrik özelliklerini incelemiştir. Tian ve ark. [14], düşük yoğunluklu polietilen (LDPE) ile eriterek karıştırma metodunu kullanarak LDPE/ZnO nanokompozitleri hazırlamış ve bu yöntemin kompozitin elektriksel özelliklerine etkisini incelemiştir. Jafarzadeh ve ark. [15], termal olarak uyarılmış faz ayırma yöntemi (TIPS) ile HDPE matrisli $\mathrm{ZnO}$ nanopartikül gömülü membranlar üretmiştir. Li ve ark. [16], eriyik karıştırma ve sıcak kalıplama işlemi yoluyla HDPE/ZnO kompozit filmler hazırlamıştır. Hazırladıkları kompozit filmlerin, ultraviyole absorpsiyonu, mekanik, antibakteriyel özellikleri ve kompozitlerin plastikleştirme davranışını incelemiştir. ZnO katkılı HDPE filmlerin, özellikle Staphylococcus aureus için uygun antibakteriyel aktivite gösterdiği sonucuna ulaşmıştır. Ersoy ve ark. [17], basit birleştirme yöntemiyle ürettikleri $\mathrm{ZnO}, \mathrm{Mg}(\mathrm{OH})_{2}$ ve $\mathrm{CaCO}_{3}$ katkılı $\mathrm{HDPE}$ matrisli kompozitlerin mekanik, termal ve morfolojik özelliklerini araştırmıştır. HAp, insan kemikleri ve dişlerine yakın kimyasal ve yapısal benzerlik gösteren iyi bilinen biyouyumlu ve biyoaktif bir malzemedir [18, 19]. HAp, toksik olmayan, inflamatuar olmayan, yüksek biyoaktiviteye sahip, biyouyumlu bir malzemedir. Bunlara ek olarak kemik bağlama, kimyasal stabilite, yüksek korozyon direnci, düşük elektriksel ve termal iletkenlik ve düşük üretim maliyeti gibi birçok üstün özelliğe sahiptir [19, 20]. HAp bu üstün özellikleri sebebiyle güncel birçok araştırmanın konusu olmuştur. Li ve ark. [21], ekstrüzyon ve enjeksiyonla kalıplama yoluyla HAp takviyeli HDPE nanokompozitler üreterek bunların termal, mekanik ve aşınma dayanımı gibi özelliklerini incelemiştir. Parra ve ark. [22], yüksek frekanslı ultrasonik radyasyon kullanarak HDPE ve poli (metil metakrilat) (PMMA) bazlı kompozit malzemeleri nanometrik HAp ile sentezlemiş, karakterize etmiş ve biyouyumluluklarını araştırmıştır. Fouad ve ark. [23], HDPE/HAp nanokompozitleri ekstruder ile üretmiş ve HAp nanopartikül yüzdesinin yapay yaşlanma üzerindeki etkilerini incelemiştir. HDPE/HAp nano kompozitlerinin yaşlanmasının, erime sıcaklığının düşmesine ve kristalliğin artmasına neden olduğu sonucuna varmıştır.

$\mathrm{Bu}$ çalışmada, HDPE matrisine $\mathrm{ZnO}$ ve HAp takviye edilerek nanokompozit malzemeler hazırlanmıştır. Toz halindeki malzemeler 1sı yardımıyla plastikleştirilmek suretiyle malzemeler arasındaki sinerjik etkinin arttırılması amaçlanmıştır. Ayrıca katkı maddesi miktarları farklı oranlarda kullanılarak hazırlanan nanokompozit malzemeler termal, kristalinite ve morfolojik özellikleri bakımından incelenmiştir. ZnO'in antibakteriyel özelliğe sahip olması ve HAp'in kemik yapısına benzerliği göz önüne alınarak, bu çalışmanın gelecekte araştırılması planlanan antibakteriyel yapay kemik uygulaması çalışmasına temel oluşturması amaçlanmıştır. Farklı oranlarda ZnO ve HAp nano boyutlu tozları (\%5.0, \%10.0, \% 15.0, \%20.0 ve \%25.0) ile katkılanmıs HDPE/ZnO ve HDPE/HAp nanokompozitleri elde etmek için toz halindeki HDPE ve nano boyutlu katkı malzeme karışımları baskı tekniği ile kalıplanmıştır. Kalıp içerisindeki nano parçacık takviyeli kompozit malzemeler HDPE’nin erime sıcaklığının üzerinde bir sıcaklığa kadar 1sıtılıp $\left(200^{\circ} \mathrm{C}\right)$ ardından oda sıcaklığına kadar soğutularak plastikleştirilmiştir. Bu basit ve etkili teknikle hazırlanan kompozit malzemelerin özellikleri ve eklenen takviye malzemelerinin etkisi X-ışını kırınım deseni (XRD), Termogravimetrik Analiz (TGA), Diferansiyel Termal Analiz (DTA) ve Taramalı Elektron Mikroskobu (SEM) metotları kullanılarak araştırılmıştır. Ayrıca eklenen takviye miktarının kompozitin özelliklerine etkisi araştırılmıştır.

\section{Deneysel Prosedür}

\subsection{Malzeme}

Polimer matris olarak toz halindeki yüksek yoğunluklu polietilen (HDPE S0464, Petkim, yoğunluğu 0,959 $\left.\mathrm{g} / \mathrm{cm}^{3}\right)$, kompozit takviye malzemesi olarak ise çinko oksit $(<50 \mathrm{~nm})(\mathrm{ZnO}$, Sigma Aldrich) ve hidroksiapatit $(<50$ $\mathrm{nm})\left(\left(\mathrm{HAp}, \mathrm{Ca}_{10}\left(\mathrm{PO}_{4}\right)_{6}(\mathrm{OH})_{2}\right.\right.$, Fluidinova) nanopartikülleri kullanılmıştır. 


\subsection{HDPE matrisli nanokompozitlerin hazırlanması}

HDPE/ZnO polimer matrisli nanokompozitler farklı konsantrasyonlarda (\%5.0, \%10.0, \%15.0, \%20.0 ve \%25.0) ZnO nanopartiküller ile HDPE karıştırılarak elde edilmiştir. HDPE ve ZnO mekanik olarak karıştırıldıktan sonra preslenerek (3MPa) $1 \mathrm{~cm}^{2}$ boyutunda silindirik numuneler şeklinde hazırlanmıştır. Hazırlanan bu numuneler aynı boyuttaki kalıba (Şekil 1) yerleştirilerek kül firınında $200{ }^{\circ} \mathrm{C}$ sıcaklıkta 1 saat bekletilerek plastikleştrilmiştir. Ardından oda sıcaklığında soğutulmuş ve böylece amaçlanan nanokompozit malzemeler hazırlanmıştır. HDPE/HAp nanokompozitler de $\mathrm{HDPE} / \mathrm{ZnO}$ nanokompozitlerin üretimindeki basamaklar takip edilerek aynı oranlarda hazırlanmıştır. Hazırlanan kompozit malzemeler ve bunların ağırlıkça yüzde bileşenleri Tablo 1.'de verilmiştir.

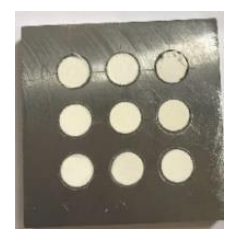

Şekil 1. Numunelerin pellet haline getirilerek firına konmadan önceki görüntüsü.

Tablo 1. Hazırlanan polimer kompozit numuneler ve bileşenleri

\begin{tabular}{lcccc}
\hline $\begin{array}{c}\text { Örnek } \\
\text { kodu }\end{array}$ & $\begin{array}{c}\text { HDPE } \\
\text { (ağırlıkça \%) }\end{array}$ & $\begin{array}{c}\text { ZnO } \\
\text { (ağırlıķa \%) }\end{array}$ & $\begin{array}{c}\text { HAp } \\
\text { (ă̆ırlıkça \%) }\end{array}$ & $\begin{array}{c}\text { Tanecik boyutu } \\
\text { (nm) }\end{array}$ \\
\hline H0 & 100 & - & - & 20.58 \\
HZn1 & 95 & 5 & - & 20.60 \\
HZn2 & 90 & 10 & - & 15.44 \\
HZn3 & 85 & 15 & - & 15.39 \\
HZn4 & 80 & 20 & - & 14.26 \\
HZn5 & 75 & 25 & - & 26.38 \\
HHA1 & 95 & - & 5 & 17.67 \\
HHA2 & 90 & - & 10 & 15.44 \\
HHA3 & 85 & - & 15 & 25.51 \\
HHA4 & 80 & - & 20 & 12.80 \\
HHA5 & 75 & - & 25 & 10.61 \\
\hline
\end{tabular}

\subsection{Karakterizasyon}

XRD analizleri Rigaku Miniflex 600 X-Işını Difraktometresi $(\lambda=0,154049 \mathrm{~nm}) \mathrm{CuK}_{\alpha}(40 \mathrm{kV} / 15 \mathrm{~mA})$ 1ş1 ̆̆ kullanılarak, $10-90^{\circ}$ aralığında $2 \theta$ kırınım açısı ve $0.02 \%$ s tarama hızında gerçekleştirilmiştir. Scherrer eşitliği (Eşitlik 1.) yardımıyla tanecik boyutu hesaplanmıştır [24].

$D=K \lambda / B \cos \theta$

Burada, D tanecik boyutunu, K kristal biçimine bağlı sabiti $(0,89), \lambda$ X-1şınının dalga boyunu $(0,154049 \mathrm{~nm})$, $\theta$ Bragg kırınım açısını ve B kırınım desenindeki maksimum yüksekliğin yarı genişlik değerini vermektedir.

Hazırlanan kompozit malzemelerin termal özelliklerini incelemek için TGA ve DTA analizleri Perkin Elmer Sapphire cihazı kullanılarak hava atmosferinde $20-900{ }^{\circ} \mathrm{C}$ sicaklık aralığında ve $20^{\circ} \mathrm{C} / \mathrm{dk}$. 1sitma hızında gerçekleştirilmiştir. Ayrıca hazırlanan kompozitlerin morfolojik özellikleri JEOL JSM-7001F Taramalı Elektron Mikroskobu (SEM) kullanılarak karakterize edilmiştir.

\section{Bulgular}

\subsection{X-Işını kırınım analizi}

HDPE, Şekil 2-a'da HDPE/ZnO ve Şekil 2-b'de ise HDPE/HAp nanokompozitlerinin X-1şınımı kırınım desenleri gösterilmiştir. Şekil.1-a ve b'de elde edilen spektrumda çok az miktarda amorf fazlı ve yüksek kristalli HDPE'ne ait olduğu belirlenen $2 \theta=21.32^{\circ}, 23.69^{\circ}, 29.12^{\circ}$ ve $35.96^{\circ}$ piklerine karş1lık (110), (200), (210) ve (020) 
düzlemlerinin olduğu belirlenmiştir. Bu $2 \theta$ değerleri, literatürdeki HDPE değerleriyle uyum içindedir [25]. Bu karakteristik pikler, nanopartiküllerin eklenmesinden sonra değişmeden kalmıştır (HZn1, HZn2 ve HZn3); bu durum, nanopartiküllerin eklenmesinin, HDPE matrisinin orijinal kristal yapısını değiştirmediğini göstermiştir [26]. Şekil 1-a'da HDPE yapısının dışında wurtzite hexagonal $\mathrm{ZnO}$ fazına ait olduğu tespit edilen $2 \theta^{\circ}=35.43^{\circ}$, $35.84^{\circ}, 47.91^{\circ}, 56.18^{\circ}, 67.49^{\circ}, 68.66^{\circ}$ ve $76.32^{\circ}$ piklerine karşl11k (002), (101), (102), (110), (112), (201) ve (202) düzlemleri XRD deseni içindeki fazlar ile birlikte görülmektedir (HZn4 ve HZn5) [27]. Bu kırınım pikleri ZnO nanopartiküllerinin HDPE matrisi içine dağıldığını göstermektedir. XRD spektrum sonucundan hazırlanan nanokompozitlerin HDPE (Uluslararası X-Işını Kırınım Veri Merkezi-International Centre of Diffraction Data; ICDD Dosya Kart No.040-1995) ortorombik (örgü sabitlerinin $a=7.50923, b=5.00097, c=2.58194$ ) ve ZnO (ICDD Dosya Kart No.076-8930) wurtzite hexagonal (örgü sabitlerinin $a=b=3.29266$ ve $c=5.08404$ ) yapiya sahip olduğu belirlenmiştir. Aynı şekilde saf HDPE ve HDPE/HAp nanokompozitleri de XRD ile incelenmiş ve elde edilen Xışınımı kırınım desenleri Şekil 2-b'de gösterilmiştir. Şekil.2-b'de HDPE yapısının dışında hexagonal HAp fazına ait olduğu tespit edilen $2 \theta=25.8^{\circ}, 31.8^{\circ}, 33.2^{\circ}, 53.1^{\circ}$ piklerine karş1lık (002), (211), (300) ve (004) düzlemleri XRD deseni içindeki fazlar ile birlikte görülmektedir (HHA4 ve HHA5). Bu kırınım pikleri HAp nanopartiküllerinin HDPE matrisi içine dağıldığını göstermektedir. XRD spektrum sonucundan hazırlanan nanokompozitlerin HAp (ICDD Dosya Kart No.09-0432) hexagonal (örgü sabitlerinin $a=b=9.41901$ ve $c=6.88315$ ) yaprya sahip olduğu belirlenmiştir [28]. Şekil 2-a ve b'de, kompozitlerin hazırlanma aşamasındaki sıcaklık ve takviye malzemenin kristalizasyonda etkili olduğu (ağırlıça \%5.0 katkı oranından \%25.0 katkı oranına artan takviye oranına göre kristalizasyonun arttığı görülmektedir. Bu durum XRD piklerinde meydana gelen daralmalardan da görülmektedir [29]. Şekil 2-a incelendiğinde HDPE/ZnO nanokompozit malzemesi için artan takviye miktarıyla kristalinite oranı arttığı halde HDPE'nin karakteristik piklerinin küçüldüğü ve ZnO'ya ait piklerin belirginleştiği gözlenmiştir. Hazırlanan HDPE/ZnO kompozitleri arasında optimum kristalinite oranları yani HDPE ve ZnO arasındaki en iyi etkileşim HZn3 ve HDPE/HAp kompoziti için optimum kristalinite değerleri HHA3 ile elde edilmiştir. \%20.0'lik HAp takviyesinden sonra (Şekil 2.b) HAp'nin karakteristik pikleri belirginleşirken HDPE'ye ait piklerde azalma görülmektedir. Scherrer eşitliği (Eşitlik 1) yardımıyla tanecik boyutu hesaplaması yapılmış ve bu değerler Tablo 1'de verilmiştir. HDPE'ye ZnO eklenmesiyle ortalama tanecik boyutu 14 ile $26 \mathrm{~nm}$ arasında ve HAp eklenmesiyle ise ortalama tanecik boyutu 10 ile $25 \mathrm{~nm}$ arasında değişim gösterdiği belirlenmiştir. Ticari olarak temin edilen $\mathrm{ZnO}$ ve HAp için tanecik boyutu $50 \mathrm{~nm}$ altındadır.

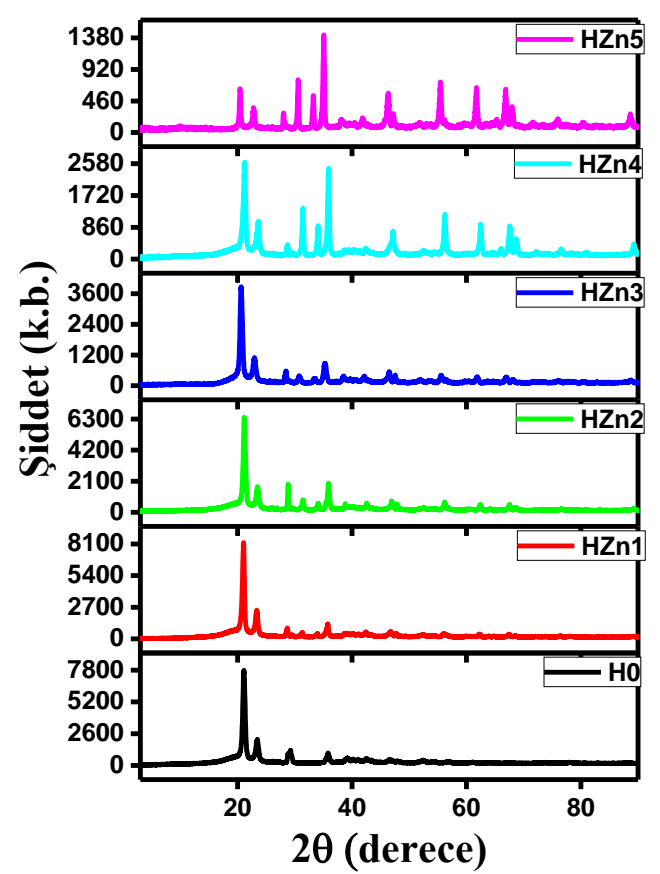

(a)

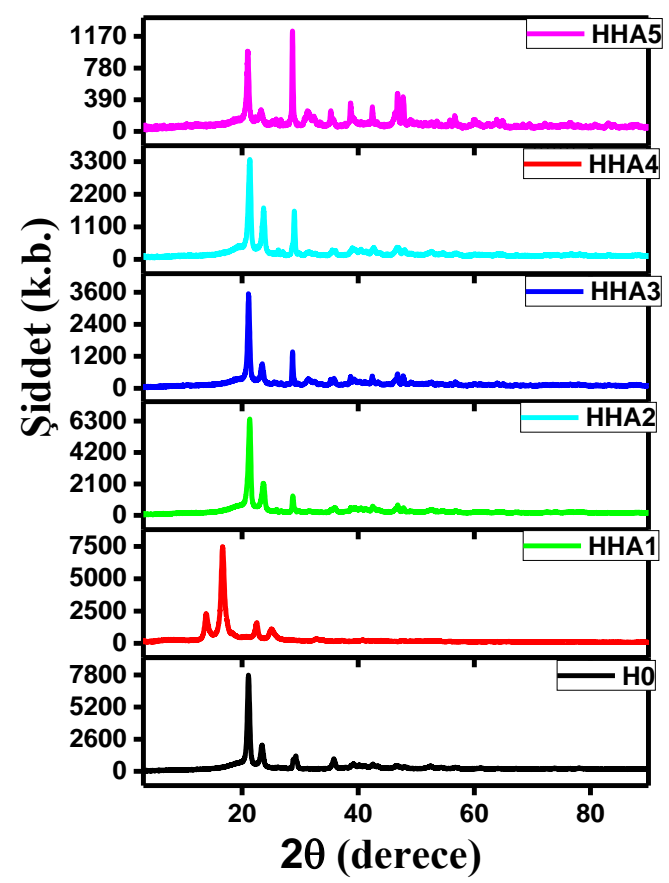

(b)

Şekil 2. a) HDPE ve $\mathrm{ZnO} / \mathrm{HDPE}$ nanokompozitlerine ve b) HDPE ve HAp/HDPE nanokompozitlerine ait $\mathrm{X}$-1şını kırınım desenleri. 


\subsection{Termal analiz}

Hazırlanan nanokompozit malzemelerin termal özelliklerini incelemek amacıyla termal gravimetrik analiz yapılmıştır. Şekil 3-a'da HDPE/ZnO nano kompozitlerinin sıcaklığa bağlı olarak ağırlığında meydana gelen değişimler gösterilmiştir. Saf HDPE'in tamamı tükenirken $\mathrm{ZnO}$ takviyeli kompozitlerde bir miktar maddenin kaldığı tespit edilmiştir. HDPE yandıktan sonra kalan miktar kompozitteki ZnO miktarı ile eşdeğerdir. Buna bağlı olarak hazırlanan kompozitin istenen bileşende ve HDPE matrisi içerisinde iyi dağıldığı belirlenmiştir. Ayrıca polimerin $440^{\circ} \mathrm{C}$ 'den itibaren bozulmaya başladığı gözlenmiştir. Şekil 3-b'de ise HDPE/HAp nanokompoziti için sıcaklığa bağlı olarak ağırlıkta meydana gelen değişim gösterilmiştir. Saf HDPE ve her bir kompozit için (ağırlıkça $\%$ 5.0, \% 10.0, \% 15.0, \%20.0 ve \%25.0 oranında HAp içeren nano kompozitler) $20-900^{\circ} \mathrm{C}$ sıcaklık aralığında ve hava atmosferinde $\mathrm{HDPE} / \mathrm{ZnO}$ nano kompozit malzemelerine benzer şekilde test edilmiştir. Hazırlanan kompozitlerin istenen şekilde ve homojen olduğu bozunma sonrasında kalan madde miktarlarından anlaşılmaktadır. Kompozitin organik kısmı (HDPE) tamamen yanarken geriye sadece anorganik HAp kalmıştır. Tablo 2'de tüm kompozitler için termogravimetrik analiz sonucunda elde edilen artan madde miktarları verilmiştir. Saf HDPE'den arta kalan madde miktarı (kül) ihmal edilebilecek düzeydeyken hazırlanan her iki tür kompozit malzemeden arta kalan madde miktarları hazırlanan bileşenler ile paralellik göstermektedir.

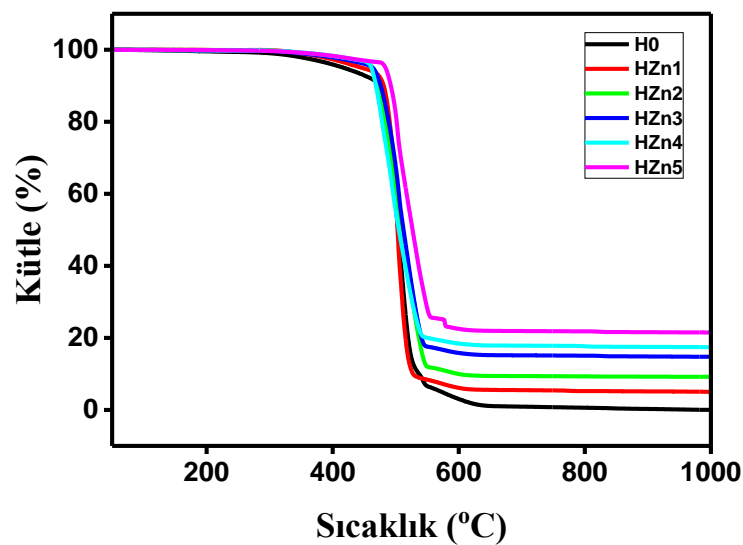

(a)

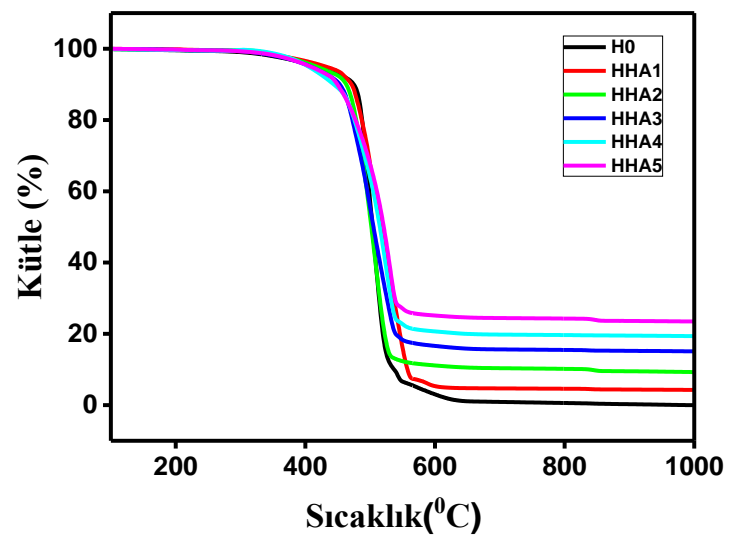

(b)

Şekil 3. a) HDPE ve HDPE/ZnO nanokompozitlere ve b) HDPE ve HDPE/HAp nanokompozitlere ait TGA grafikleri.

Tablo 2. Hazırlanan kompozitler için termogrametrik analiz verileri

\begin{tabular}{ll}
\hline Örnek adı & \multicolumn{1}{c}{$\begin{array}{c}\text { Artık miktarı } \\
(\boldsymbol{\%})\end{array}$} \\
\hline H0 & 0.0025 \\
HZn1 & 4.9975 \\
HZn2 & 9.1944 \\
HZn3 & 14.7416 \\
HZn4 & 17.4227 \\
HZn5 & 21.5005 \\
HHA1 & 4.2728 \\
HHA2 & 9.2792 \\
HHA3 & 15.0940 \\
HHA4 & 19.3686 \\
HHA5 & 23.4754 \\
\hline
\end{tabular}

Şekil 4-a incelendiğinde artan sıcaklıkla 1sı akışının bozunma sıcaklığına kadar stabil olduğu gözlenmektedir. Bozunmanın başlamasıyla birlikte kararlı hal ortadan kalkmış ve 1sı akışı ani bir artış göstermiştir. Bununla birlikte HO, HZn1, HZn2, HZn3, HZn4 ve HZn5' in bozunmaya başlama sicaklığ 1 sırasıyla 440, 461, 461, 465, 465 ve $485^{\circ} \mathrm{C}$ 'dir. Bu anorganik katkı maddesi ZnO miktarının artmasından kaynaklanmaktadır. HDPE/HAp kompozitleri için bozunmaya başlama sıcaklığı $445^{\circ} \mathrm{C}$ olarak belirlenmiştir. 
HDPE/ZnO kompozitine \%5.0'lik ZnO takviye edilmesiyle 1sı akısı ani bir atış göstererek 40'tan 380'e yükselmiştir. Bu sonuçlara bakıldığında malzemenin termal kararlığındaki değişimin HZn3 nanokompoziti nde optimum düzeyde olduğu belirlenmiştir. Şekil 4-b'de ise HDPE/HAp nanokompozitlerinin sicaklığa bağlı olarak ısı akısıındaki değişimler verilmiştir. HDPE/ZnO nano kompozitlerine benzer olarak burada da HHA1'in 1sı akısı aniden artarken, dolgu malzemesi bileşeni arttıkça 1S1 akısında azalmanın meydana geldiği görülmektedir. HDPE/HAp kompozitleri için bozunmaya başlama sıcaklığ $1445^{\circ} \mathrm{C}$ olarak belirlenmiştir. Ayrıca saf HDPE, kompozitlere göre bozunma sıcaklığındaki 1sı akısı daha düşüktür. HDPE/HAp nanokompozitlerin de HDPE/ZnO nanokompozitlerine benzer özellikler gösterdiği ve optimum termal kararlılığa HHA3 kompoziti ile ulaşıldığı gözlenmiştir.

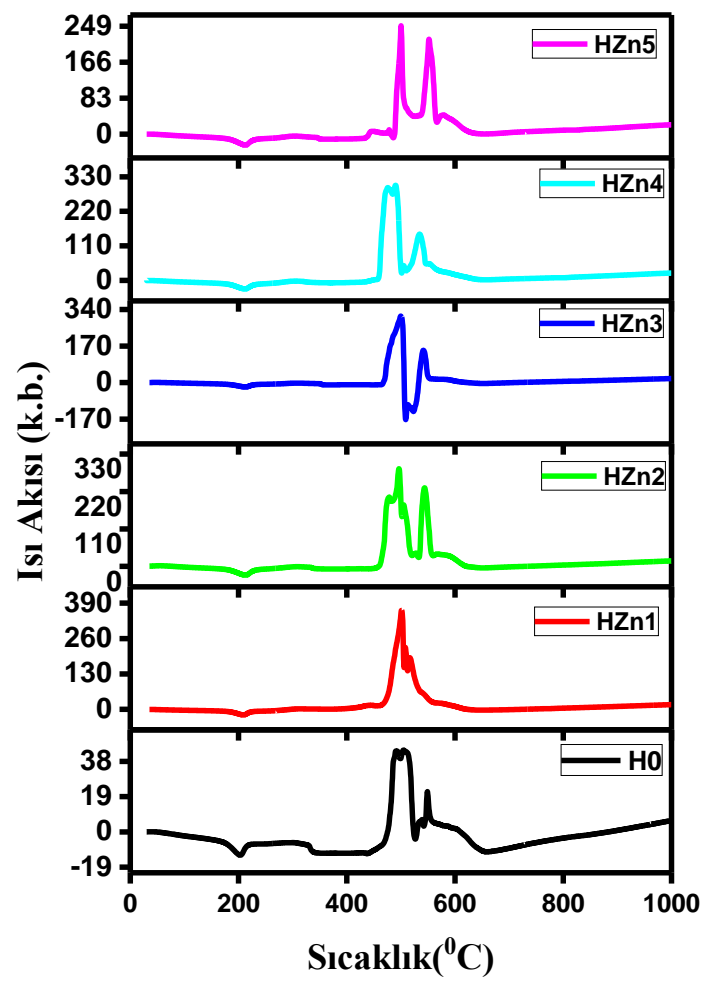

(a)

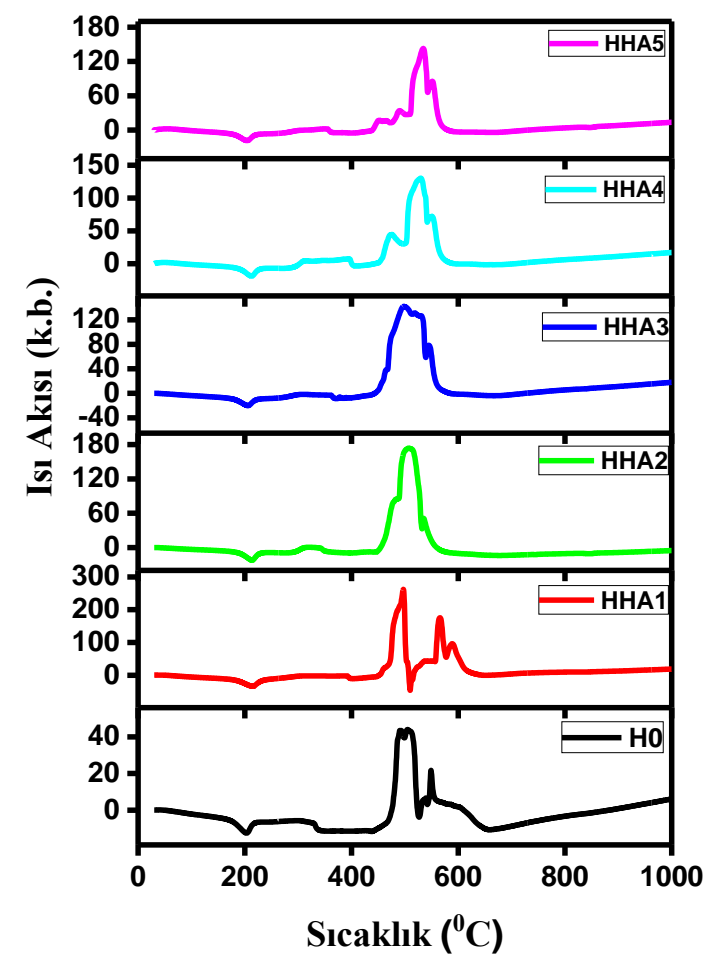

(b)

Şekil 4. a) HDPE ve HDPE/ZnO ve b) HDPE ve HAp/HDPE nanokompozitlerinin DTA eğrileri.

\subsection{Yüzey karakterizasyonu}

Şekil 5-a'da HDPE ve farklı konsantrasyonlarda ZnO kullanılarak hazırlanmış nanokompozit malzemeler için SEM görüntüleri verilmiştir. HDPE yüzeyi oldukça düz ve pürüzsüzken HDPE/ZnO kompozitlerinin yüzeyinde tabakalanmalar olduğu ve $\mathrm{ZnO}$ konsantrasyonunun artışına bağlı olarak bu tabakalanmaların arttı̆̆ gözlenmiştir. SEM görüntüleri incelendiğinde ZnO’nun HDPE içerisinde iyi bir biçimde dağıldığı anlaşılmaktadır. Şekil 5-b'de ise HDPE/HAp nonokompozitlerine ait SEM görüntüleri verilmiştir. HAp konsantrasyonu arttıkça yapıda meydana gelen tabakalanma net bir biçimde gözlenmektedir. Ayrıca görüntüler incelendiğinde HAp'nin HDPE matris içerisinde iyi bir dağılım gösterdiği. görülmektedir. HDPE/ZnO ve HDPE/HAp nanokompozitlerin her ikisinde de tabakalanmalar meydana gelmesine rağmen iki kompozitin morfolojik farklılıkları net bir biçimde görülmektedir. 


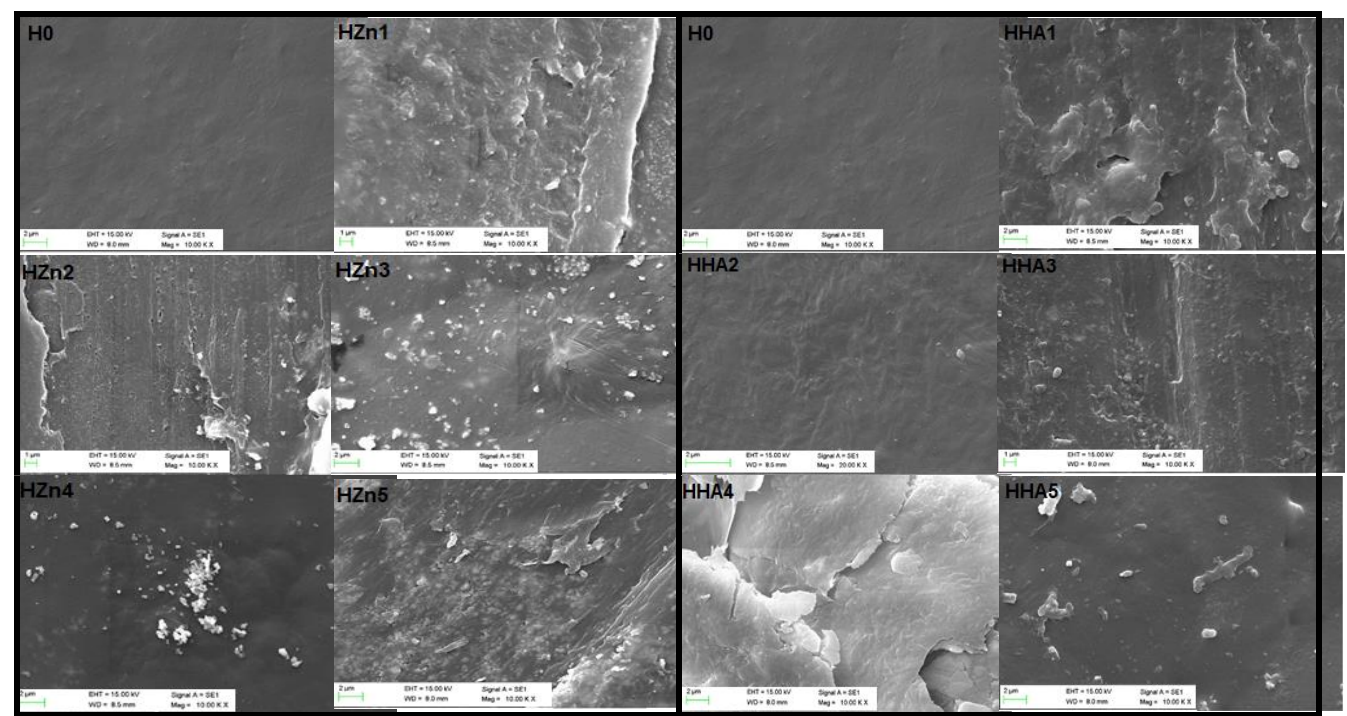

(a)

(b)

Şekil 4. a) HDPE ve HDPE/ZnO nanokompozitlere ve b) HDPE ve HAp/HDPE nanokompozitlere ait SEM görüntüleri.

\section{Sonuçlar}

$\mathrm{Bu}$ çalışmada HDPE matrisine farklı oranlarda nano boyutlu $\mathrm{ZnO}$ ve HAp tozları eklenerek nanokompozit malzemeler üretilmiştir. Nanopartikül takviyesiyle birlikte HDPE matrisinin kristal yapısını değiştirmediği ve nanopartiküllere ait $2 \theta$ piklerinin mevcut olduğu belirlenmiştir. Bu HDPE matris içinde nano partiküllerin iyi bir biçimde dağıldığını göstermektedir. Scherrer eşitliği ile tanecik boyutları hesaplanmış, saf HDPE için $20.58 \mathrm{~nm}$, HDPE/ZnO nanokompozitler için 14-26 nm arasında ve HDPE/HAp nanokompozitler için 10-25 nm arasında değerler aldığı tespit edilmiştir. Ancak artan takviye oranı ile birlikte kristalinite armasına rağmen, HDPE/ZnO için ve HDPE/HAp için \%15,0 lik takviyenin ardından HDPE'ye ait piklerin küçüldüğü ve kaybolduğu gözlenmiştir. Ayrıca 1sı akısının her iki kompozit için de takviye maddesi ile birlikte aniden arttığı, ardından artan takviye miktarı ile önce azaldığı sonra tekrar arttığı belirlenmiştir. Saf HDPE'nin bozunmaya başlama sıcaklığ $440^{\circ} \mathrm{C}$ iken HDPE/ZnO nanokompozitleri için ortalama $465^{\circ} \mathrm{C}$ ve HDPE/HAp nanokompozitler için $445^{\circ} \mathrm{C}$ olarak tespit edilmiştir. Kullanılan teknik ile üretilen kompozit malzemelerin iyi dağıldığı, artan takviye miktarıyla birlikte nano kompozitlerin kristalinite ve termal kararlılıklarında arttış gözlendiği ve morfolojilerinde saf HDPE'den farklı olarak tabakalanmaların meydana geldiği tespit edilmiştir. Termal ve kristalinite çalışmaları neticesinde optimum takviye oranı HDPE/ZnO ve HDPE/HAp nanokompozitleri için ağırlıkça \% 15.0 olarak belirlenmiştir.

\section{Kaynaklar}

[1] Tanniru M, Yuan Q, Misra R. On significant retention of impact strength in clay-reinforced high-density polyethylene (HDPE) nanocomposites. Polymer 2006; 47(6): 2133-2146.

[2] Grigoriadou I, Paraskevopoulos K, Chrissafis K, Pavlidou E, Stamkopoulos TG, Bikiaris D. Effect of different nanoparticles on HDPE UV stability. Polymer Degradation and Stability 2011; 96(1): 151-163.

[3] Gilmer TC, Williams M. Polymer mechanical properties via a new laboratory tensile tester. Journal of Chemical Education 1996; 73(11):1062.

[4] Sahebian S, Zebarjad SM, Sajjadi SA, Sherafat Z, Lazzeri A. Effect of both uncoated and coated calcium carbonate on fracture toughness of HDPE/CaCO3 nanocomposites. Journal of Applied Polymer Science 2007; 104(6): 3688-3694.

[5] Ammala A, Hill A, Meakin P, Pas SJ, Turney TW. Degradation studies of polyolefins incorporating transparent nanoparticulate zinc oxide UV stabilizers. Journal of Nanoparticle Research 2002; 4(1-2): 167-174.

[6] Ponnamma D, Cabibihan JJ, Rajan M, Pethaiah SS, Deshmukh K, Gogoi JP, Pasha SK, Ahamed MB, ve diğerleri. optimization and applications of $\mathrm{ZnO}$ /polymer nanocomposites. Materials Science and Engineering: C 2019; 98, 12101240.

[7] Devaraju A, Sivasamy P, Loganathan GB. Mechanical properties of polymer composites with ZnO nano-particle. Materials Today: Proceedings, 2019. 
[8] Ahmed M, Meyer WE, Nel JM. Structural, optical and electrical properties of the fabricated Schottky diodes based on $\mathrm{ZnO}, \mathrm{Ce}$ and Sm doped $\mathrm{ZnO}$ films prepared via wet chemical technique. Materials Research Bulletin 2019; 115, 12-18.

[9] Çolak, H, Karaköse E. Tm-doped ZnO nanorods as a TCO for PV applications. Journal of Rare Earths 2018; 36(10): 1067-1073.

[10] Zak AK, Ghanbari A, ShekoftehNarm T. The effect of molybdenum on optical properties of ZnO nanoparticles in Ultraviolet-Visible region. Advanced Powder Technology 2017; 28(11): 2980-2986.

[11] Bhati VS, Hojamberdiev M, Kumar M. Enhanced sensing performance of $\mathrm{ZnO}$ nanostructures-based gas sensors: A review. Energy Reports, 2019.

[12] Mallakpour S, Behranvand V. Nanocomposites based on biosafe nano $\mathrm{ZnO}$ and different polymeric matrixes for antibacterial, optical, thermal and mechanical applications. European Polymer Journal 2016; 84, 377-403.

[13] Mansour SA, Elsad R, Izzularab M. Dielectric investigation of high density polyethylene loaded by ZnO nanoparticles synthesized by sol-gel route. Journal of Sol-Gel Science and Technology 2016; 80(2): 333-341.

[14] Tian F, Lei Q, Wang X, Wang Y. Investigation of electrical properties of LDPE/ZnO nanocomposite dielectrics. IEEE Transactions on Dielectrics and Electrical Insulation 2012; 19(3): 763-769.

[15] Jafarzadeh Y, Yegani R, Sedaghat M. Preparation, characterization and fouling analysis of $\mathrm{ZnO} /$ polyethylene hybrid membranes for collagen separation. Chemical Engineering Research and Design 2015; 94, 417-427.

[16] Li SC, Li YN. Mechanical and antibacterial properties of modified nano-ZnO/high-density polyethylene composite films with a low doped content of nano-ZnO. Journal of Applied Polymer Science 2010;116(5): 2965-2969.

[17] Ersoy S, Taşdemir M. Zinc oxide ( $\mathrm{ZnO})$, magnesium hydroxide $[\mathrm{Mg}(\mathrm{OH}) 2]$ and calcium carbonate $(\mathrm{CaCO} 3)$ filled HDPE polymer composites: Mechanical, thermal and morphological properties. Marmara Fen Bilimleri Dergisi 2012; 24(4): 93104.

[18] Dorozhkin SV. Calcium orthophosphates as bioceramics: state of the art. Journal of Functional Biomaterials 2010; 1(1): 22-107.

[19] Dou Y, Cai S, Ye X, Xu G, Hu H, Ye X. Preparation of mesoporous hydroxyapatite films used as biomaterials via solgel technology. Journal of Sol-Gel Science and Technology 2012; 61(1): 126-132.

[20] Dorozhkin SV. Bioceramics of calcium orthophosphates. Biomaterials 2010 ; 31(7): 1465-1485.

[21] Li K, Tjong SC. Preparation and mechanical and tribological properties of high-density polyethylene/hydroxyapatite nanocomposites. Journal of Macromolecular Science, Part B 2011; 50(7): 1325-1337.

[22] Parra C, Gonzalez G, Albano C. Synthesis and characterization of composite materials HDPE/HA and PMMA/HA prepared by sonochemistry. In Macromolecular Symposia 2009; Wiley Online Library.

[23] Fouad H, Elleithy R, Alothman OY. Thermo-mechanical, wear and fracture behavior of high-density polyethylene/hydroxyapatite nano composite for biomedical applications: effect of accelerated ageing, Journal of Materials Science \& Technology 2013; 29(6): 573-581.

[24] Borchert H, Shevchenko EV, Robert A, Mekis I, Kornowski A, Grübel G, Weller H. Determination of nanocrystal sizes: a comparison of TEM, SAXS, and XRD studies of highly monodisperse CoPt3 particles. Langmuir 2005; 21(5): 19311936.

[25] Alaburdaite R, Paluckiene E, Grevys S. Comparison of the surface characteristics of polyethylene and polypropylene films and polyester textile coated with electroconductive copper sulphide thin films. Chalcogenide Letters 2016; 13(12): 529536.

[26] He Q, Yuan T, Zhu J, Luo Z, Haldolaarachchige N, Sun L, Khasanov A, Li Y, ve diğerleri. Magnetic high density polyethylene nanocomposites reinforced with in-situ synthesized Fe-FeO core-shell nanoparticles. Polymer 2012; 53(16): 3642-3652.

[27] Shen L, Bian X, Lu X, Shi L, Liu Z, Chen L, Hou Z, Fan K. Preparation and characterization of ZnO/polyethersulfone (PES) hybrid membranes. Desalination 2012; 293, 21-29.

[28] Paz A, Guadarrama D, López M, González E, Brizuela JN, J Aragón. A comparative study of hydroxyapatite nanoparticles synthesized by different routes. Química Nova 2012; 35(9): 1724-1727.

[29] Kaygili O, Ates T, Keser S, Al-Ghamdi AA, Yakuphanoglu F. Controlling of dielectrical properties of hydroxyapatite by ethylenediamine tetraacetic acid (EDTA) for bone healing applications. Spectrochimica Acta Part A: Molecular and Biomolecular Spectroscopy 2014; 129, 268-273. 